\title{
COMPRIMENTO DE ESTACAS E PARTE DO RAMO NA FORMAÇÃO DE MUDAS DE ACEROLEIRA $^{1}$
}

\author{
ROSIANE DE LOURDES SILVA DE LIMA², DALMO LOPES DE SIQUEIRA ${ }^{3}$, OLMAR BALLER WEBER ${ }^{4}$, \\ JAIRO OSVALDO CAZETTA ${ }^{5}$
}

\begin{abstract}
RESUMO - A capacidade rizogênica, a brotação e o vigor de estacas caulinares de aceroleira foram avaliados em condições de casa de vegetação na Embrapa Agroindústria Tropical, em Fortaleza-CE, no período de novembro de 2000 a janeiro de 2001, objetivando determinar a parte do ramo e o tamanho mais apropriado para estaquia. O delineamento experimental foi inteiramente casualizado, no esquema fatorial 3x3, correspondendo a três posições no ramo (apical, mediano e basal) e três comprimentos de estacas (10; 15 e $20 \mathrm{~cm}$ ), com três repetições de 10 estacas por parcela. As estacas, colhidas de plantas com 2,5 anos de idade, foram plantadas em tubetes de $288 \mathrm{~cm}^{3}$ contendo uma mistura de casca de arroz carbonizada e vermicomposto, na proporção volumétrica de 2:3, e cultivadas por um período de 60 dias sob condições de nebulização intermitente. Avaliaram-se a percentagem de estacas enraizadas, o peso da matéria seca do sistema radicular e parte aérea, o número de folhas, de gemas sem brotação e as ramificações emitidas por estaca. Os resultados indicaram que estacas caulinares com 10 centímetros de comprimento e colhidas da porção mediana dos ramos são mais apropriadas para a produção de mudas de aceroleira por estaquia, sob condições de casa de vegetação com nebulização intermitente.
\end{abstract}

Termos para indexação: Malpighia emarginata, estaquia, tipo de estaca, tamanho.

\section{SIZE AND PART OF THE BRANCH TO BE USED AS BARBADOS CHERRY CUTTINGS}

ABSTRACT - The rhizogenic capacitity, sprouting and vigor of cuttings from barbados cherry (Malpighia emarginata D.C) were evaluated in greenhouse conditions at the EMBRAPA - National Center for Research of Tropical Agroindustry, Fortaleza-CE, from November 2000 to January 2001, aiming to identify the best branch part and size for cuttings preparation. The experiment was conducted in a completely randomized design, in a $3 \times 3$ factorial scheme, corresponding to three positions on the branch (apical, median and basal) and three length (10, 15 and $20 \mathrm{~cm})$, with three replications composed by 10 cuttings each, and cultured on tubets of $288 \mathrm{~cm}^{3}$, filled wich a misture of organic matter (vermicompost) and carbonized rice husks (3:2 volumetric proportion), and cultivated in a greenhouse with intermittent mist. After 60 days were evaluated the percentage of surviving cuttings, rooted cuttings, roots and aerial part dry matter, number of leaves, not developed meristems, and number of new branches per cutting. Results indicated that vegetative propagation by cuttings of Barbados cherry is a feasible method, by using cuttings with $10 \mathrm{~cm}$ length, taken from the middle positions of the branch, and cultured under greenhouse conditions and intermittent mist.

Index terms: Malpighia emarginata, cuttings, branch for cuttings, vigor.

\section{INTRODUÇÃO}

A aceroleira (Malpighia emarginata D.C) tem sido cultivada nas diferentes regiões brasileiras e a sua produtividade varia em função do processo de propagação e da seleção das plantas-matrizes para a formação de mudas, além de outros fatores. Assim, de acordo Paiva et al. (1999), têm-se buscado genótipos com capacidade de produzir mais de $100 \mathrm{~kg} / \mathrm{planta} /$ ano de frutos com 8-10 g cada, com polpa avermelhada e teor de vitamina $\mathrm{C}$ superior a $2.000 \mathrm{mg} / 100 \mathrm{~g}$.

Dentre os métodos clássicos de propagação vegetativa, citase a estaquia, e sua viabilidade na fruticultura está condicionada à facilidade de enraizamento de cada espécie ou cultivar (Gondim et al., 2001) e à capacidade de desenvolvimento do sistema radicular (Hartman et al., 1997), que são duas características fundamentais para o posterior desenvolvimento da planta na área de produção. A técnica consiste na multiplicação de plantas usando segmentos de ramos, providos de gemas meristemáticas com capacidade para emitir raízes adventícias, comumente denominados de estacas (Hartman et al., 1997).

A estaquia permite obter um grande número de mudas a partir de poucas plantas-matrizes, bem como exige um espaço relativamente pequeno. É uma técnica simples que apresenta baixo custo e não requer treinamento especializado como no caso da enxertia ou da micropropagação (Braga et al., 1997; Hartman et al., 1997).

Apesar das vantagens do método de estaquia, a escolha do ramo e a posição da retirada da estaca no ramo são fatores que induzem grande variação no desenvolvimento da muda de aceroleira e que ainda não estão bem definidos. Bezerra et al. (1991) obtiveram entre 73,8 e $75,5 \%$ de enraizamento em estacas com duas folhas e colhidas na posição apical do ramo; Gonzalez et al. (1994) obtiveram de 35\% a 53\% para estacas coletadas nas posições basal e mediana do ramo, bem como $72 \%$ para estacas coletadas no ápice do ramo, enquanto Lima et al. (1992) obtiveram até 66\% de enraizamento para estacas colhidas na posição basal e mediana do ramo.

A posição da estaca no ramo e o tamanho a ser usado precisam ser bem definidos. A escolha e o preparo inadequado das estacas, o grau de experiência que o agricultor tem com a espécie e o potencial genético de enraizamento da mesma são fatores que podem resultar em elevadas taxas de mortalidade das estacas, inviabilizando o processo de produção de mudas (Gondim et al., 2001). A variabilidade genética dentro da espécie também é outro fator que influencia na capacidade rizogênica das estacas e no comportamento das mudas de aceroleira (Costa et al., 2000; Gomes et al., 2001).

De forma geral, sabe-se que estacas caulinares colhidas da posição apical do ramo têm menor grau de lignificação, células meristemáticas com metabolismo mais ativo e ausência ou menor quantidade de compostos fenólicos, o que facilita o enraizamento e o brotamento (Hartman et al., 1997). Porém, baixos índices de pegamento podem ocorrer devido à maior predisposição destas estacas tenras em perderem umidade. Além disso, Nicoloso et al. (1999) afirmam que tais estacas também possuem limitada reserva de nutrientes orgânicos e inorgânicos em seus tecidos, sendo esta uma causa do baixo índice de sobrevivência. Outro fator que influencia na capacidade de enraizamento das estacas é o seu teor de carboidratos. Fachinello et al. (1994), trabalhando com pessegueiro, afirmaram que, ao longo do ramo, o conteúdo de carboidratos e de substâncias promotoras e inibidoras de enraizamento nos tecidos apresenta variação, sendo um dos motivos pelos quais as estacas coletadas de diferentes porções do ramo tendem a diferir quanto ao potencial de enraizamento. Contudo, para a cultura

\footnotetext{
${ }^{1}$ (Trabalho 204/2005). Recebido: 15/12/2005. Aceito para publicação: 06/03/2006.

${ }^{2} \mathrm{Eng}^{\mathrm{a}} \mathrm{Ag}^{\mathrm{a}}$ Ms. Doutoranda em Agronomia (Produção Vegetal) - Unesp - Universidade Estadual Paulista - Jaboticabal-SP. limarosiane@yahoo.com.br

${ }^{3}$ Prof. Adjunto, D.Sc., Universidade Federal de Viçosa, Departamento de Fitotecnia, 36570-000, Viçosa-MG. siqueira@ufv.br.

${ }^{4}$ Eng $^{\circ}$ Ag $^{\circ}$, D.Sc., Embrapa Agroindústria Tropical. Av. Dra. Sara Mesquita, 2270. Pici, 60511-110, Fortaleza-CE. weber@cnpat.embrapa.br.

${ }_{5}^{5}$ Prof. Adjunto, D.Sc., Unesp - Universidade Estadual Paulista, Departamento de Tecnologia, 14884-900, Jaboticabal-SP. cazetta@fcav.unesp.br .
} 
da aceroleira, Gomes et al. (2000) mencionaram que a propagação comercial de mudas é mais viável e produtiva quando se utilizam segmentos caulinares colhidos da posição terminal e subterminal dos ramos.

Quanto ao tamanho da estaca, poucas referências fazem alusão a este assunto em aceroleira. Paiva et al. (1999) mencionam que estacas curtas poderão ser usadas quando há necessidade de propagar genótipos superiores que apresentem pouca disponibilidade de plantas-matrizes, mas não se referem a índices de sobrevivência e qualidade das mudas. Por outro lado, estacas longas podem tornar-se mais suscetíveis à desidratação devido à grande superfície exposta ao ambiente e à maior demanda de água para suprir a grande quantidade de tecido vivo. Lima et al. (1992), avaliando a capacidade de enraizamento de estacas herbáceas e semilenhosas de aceroleira, constataram que o grau de lignificação das estacas não influenciou na percentagem de enraizamento das mesmas e, neste aspecto, verificaram superioridade das estacas com $15 \mathrm{~cm}$ de comprimento, quando comparado às de $7,5 \mathrm{~cm}$.

Apesar de existirem trabalhos publicados sobre a produção de mudas de aceroleira por estaquia, o grande número de variáveis envolvidas no processo faz com que várias informações sejam contrastantes, deixando ainda muitas incertezas para o produtor de mudas. Em função disso, idealizou-se este estudo com o objetivo de determinar a posição de colheita da estaca no ramo e o comprimento mais adequado à produção de mudas de aceroleira.

\section{MATERIAL E MÉTODOS}

O experimento foi conduzido em casa de vegetação na Embrapa Agroindústria Tropical, com sistema de nebulização intermitente, por um período de 60 dias após o plantio das estacas (novembro de 2000 a janeiro de 2001). Utilizaram-se estacas de três tamanhos e três posições de ramos semilenhosos, colhidos de plantas-matrizes com 2,5 anos de idade. Foi escolhida a progênie 91, proveniente da coleção de genótipos de aceroleiras mantida na Embrapa Agroindústria Tropical, em PacajusCE, em função das boas características de porte e arquitetura da copa, bem como do tamanho, coloração e teor de vitamina $\mathrm{C}$ de seus frutos, que recomendam sua multiplicação para produção.

Os ramos foram colhidos nas primeiras horas da manhã e segmentados em estacas da porção apical, mediana e basal, com 10; 15 e $20 \mathrm{~cm}$ de comprimento. Após a seleção das estacas mais uniformes, foi removida parte de suas folhas, deixando-se 2 pares na ponta da estaca, sendo que, destas folhas, foi deixado apenas $1 / 3$ da área foliar. As estacas retiradas das posições apicais, medianas e basais do ramo apresentavam diâmetro médio de 0,$4 ; 0,5$ e $0,7 \mathrm{~cm}$, respectivamente.

As estacas, classificadas conforme a posição de coleta no ramo e o comprimento, foram mergulhadas durante 5 segundos em uma solução de Benomyl a 0,2\%. Em seguida, suas bases foram colocadas numa solução de ácido indolbutírico (2000 ppm) durante 5 segundos. Na seqüência, foram plantadas em tubetes de polietileno, com capacidade para $288 \mathrm{~cm}^{3}$, contendo a mistura de casca de arroz carbonizada e vermicomposto (húmus de minhoca), na proporção volumétrica de $40 \%$ e $60 \%$, respectivamente. As características químicas dos materiais utilizados na mistura encontramse apresentadas na Tabela 1.

Os nove tratamentos experimentais foram constituídos pela combinação de três posições de coleta das estacas nos ramos e três comprimentos de estacas, arranjados no esquema fatorial de $3 \times 3$, com três repetições, perfazendo 27 unidades experimentais, no delineamento inteiramente casualizado. Cada parcela foi constituída por 10 tubetes contendo, cada uma, uma estaca. Paralelamente, foi conduzida uma parcela onde periodicamente se retiravam estacas com a finalidade de monitorar o aparecimento de doenças e o desenvolvimento das raízes. O conjunto experimental foi mantido na casa de vegetação sob um sistema de nebulização intermitente regulado para ativação três vezes ao dia, durante intervalos de quinze minutos cada. Completados os 60 dias do plantio das estacas, foram avaliadas porcentagens de estacas enraizadas (PER), comprimento médio da maior raiz (CMR), massa seca de raízes (MSR), número de gemas intumescidas e sem brotação (NSB), número de ramos desenvolvidos (NRD), número de folhas (NF), massa seca da parte aérea (MSPA) e índice de sobrevivência (IS).

Os dados foram submetidos à análise de variância, avaliandose os fatores pelo teste $\mathrm{F}$, e as médias foram comparadas pelo teste de Tukey, a 5\% de probabilidade.

\section{RESULTADOS E DISCUSSÃO}

O substrato utilizado foi apropriado e verificou-se que o período em que houve maior emissão de raízes pelas estacas ocorreu em torno dos 22 dias do plantio, para todos os tratamentos. A análise de variância indicou efeito significativo da posição de coleta das estacas no ramo, do comprimento das mesmas, bem como da interação destes fatores. As médias obtidas, acompanhadas pelos resultados do teste de Tukey, encontram-se apresentadas na Tabela 2.

Quando foram avaliadas as estacas apicais com $10 \mathrm{~cm}$ de comprimento, verificou-se que, apesar de terem iniciado o processo de emissão de raízes, não sobreviveram até os 60 dias após o plantio. Observou-se que tais estacas morreram logo após o início do desenvolvimento das raízes, sugerindo que a morte possa ter ocorrido devido à baixa disponibilidade de reservas nutritivas necessárias para sustentar seu desenvolvimento (Nicoloso et al., 1999). Embora a demanda por água seja um fator importante, a ausência de brotos na parte aérea destas estacas (cerca de 20 dias após o plantio) é um indicativo de que este não foi o principal fator responsável pela elevado grau de mortalidade observado.

A maior porcentagem de enraizamento $(83,33 \%)$ ocorreu nas estacas de $15 \mathrm{~cm}$ e retiradas da posição apical, seguida pela daquelas de $10 \mathrm{~cm}$ retiradas da parte mediana $(63,33 \%)$. As estacas com $15 \mathrm{~cm}$ colhidas da parte média do ramo e as de $20 \mathrm{~cm}$ colhidas das partes apical e mediana apresentaram menores porcentagens de enraizamento, mas ainda acima de $50 \%(56,33 \% ; 58,33 \%$ e $56,66 \%$, respectivamente), enquanto as demais abaixo de $50 \%$. Os resultados sugerem que materiais com menor grau de lignificação, como é o caso daqueles colhidos da posição apical, apresentam condições fisiológicas adequadas para a emissão de novas estruturas como raízes adventícias. Entretanto, o tamanho das estacas parece ser fundamental para a sua sobrevivência, pois estacas apicais com $10 \mathrm{~cm}$ de comprimento não sobreviveram, mesmo após a emissão de raízes. Resultados opostos foram obtidos por Lima et al. (1992) que, avaliando a capacidade de enraizamento de estacas herbáceas e semilenhosas de aceroleira, observaram que o grau de lignificação da estaca não influenciou em sua percentagem de enraizamento. Por outro lado, Lima et. al. (1992), estudando os efeitos da consistência física (lenhosa e semilenhosa) e do comprimento de estacas simples e enfolhadas de aceroleira $(7-8 \mathrm{~cm} \mathrm{e} 14-16 \mathrm{~cm})$, constataram que o tecido com menor grau de lignificação apresentou maior tendência para enraizar que aqueles materiais mais lignificados.

Estacas retiradas da posição basal do ramo, independentemente do comprimento, apresentaram as menores percentagens de

TABELA 1 - Características químicas do vermicomposto e da casca de arroz carbonizada, utilizados na formulação do substrato para produção de mudas de aceroleira.

\begin{tabular}{|c|c|c|c|c|c|c|c|c|c|c|}
\hline \multirow[b]{2}{*}{ COMPONENTE } & \multirow[b]{2}{*}{$\mathrm{pH}^{*}$} & $\mathrm{Ca}$ & $\mathrm{Mg}$ & $\mathrm{Na}$ & $\mathrm{K}$ & $\mathrm{P}$ & $\mathrm{Fe}$ & $\mathrm{Zn}$ & $\mathrm{Mn}$ & $\mathrm{Cu}$ \\
\hline & & \multicolumn{9}{|c|}{$---------------------------\mathrm{mg} / \mathrm{dm}^{3}-------------------------1$} \\
\hline Vermicomposto & 6,5 & 12,6 & 7,2 & 235 & 445 & 386 & 21,8 & 11,2 & 12,3 & 2,3 \\
\hline Casca de arroz carbonizada & 7,0 & 0,5 & 0,5 & 37 & 490 & 104 & 11,4 & 2,2 & 8,0 & 0,7 \\
\hline
\end{tabular}

* pH em água $(1: 2,5)$. 
TABELA 2 - Porcentagem de estacas enraizadas (PER), comprimento médio de raiz (CMR), massa da matéria seca das raízes (MSR), número de gemas que não brotaram (GNB), número de ramificações desenvolvidas (NRD), número de folhas (NF), massa da matéria seca da parte aérea (MSPA), índice de sobrevivência (IS) de aceroleira (Malpighia emarginata D.C). Fortaleza-CE, 2001.

\begin{tabular}{|c|c|c|c|c|c|c|c|c|c|}
\hline \multirow[b]{2}{*}{ Posição no ramo } & \multicolumn{9}{|c|}{ Comprimento das estacas $(\mathrm{cm})$} \\
\hline & 10 & 15 & 20 & 10 & 15 & 20 & 10 & 15 & 20 \\
\hline & --------------- & PER & ----------------- & ------------ & - CMR (cn & ---------------- & ------- & - MSR ( & -------------- \\
\hline Apical & $0,00 \mathrm{cC}$ & $83,33 \mathrm{aA}$ & $58,33 \mathrm{bA}$ & $0,00 \mathrm{bB}$ & $17,81 \mathrm{aA}$ & $14,66 \mathrm{aA}$ & $0,00 \mathrm{cB}$ & $0,14 \mathrm{bB}$ & $0,70 \mathrm{aB}$ \\
\hline Mediana & $63,33 \mathrm{aA}$ & $56,66 \mathrm{aB}$ & $56,66 \mathrm{aA}$ & $18,66 \mathrm{aA}$ & $15,83 \mathrm{aA}$ & $16,66 \mathrm{aA}$ & $0,66 \mathrm{aA}$ & $0,52 \mathrm{aA}$ & $0,66 \mathrm{aA}$ \\
\hline \multirow[t]{2}{*}{ Basal } & $45,00 \mathrm{aB}$ & $33,33 \mathrm{bB}$ & $36,66 \mathrm{bB}$ & $18,66 \mathrm{aA}$ & $16,50 \mathrm{aA}$ & $17,00 \mathrm{aA}$ & $0,19 \mathrm{bB}$ & $0,56 \mathrm{aA}$ & $0,44 \mathrm{aA}$ \\
\hline & ------ GNB & (unidade/ & estaca)-------- & $-------\mathrm{NI}$ & (unidade) & staca)------ & ----1 & (unidade & ca) ----- \\
\hline Apical & $0,00 \mathrm{bB}$ & $6,00 \mathrm{aA}$ & $5,00 \mathrm{aA}$ & $0,00 \mathrm{bB}$ & $3,00 \mathrm{aA}$ & $2,00 \mathrm{aA}$ & $0,00 \mathrm{bB}$ & $27,66 \mathrm{aA}$ & $22,66 \mathrm{aA}$ \\
\hline Mediana & $3,50 \mathrm{bA}$ & $6,33 \mathrm{aA}$ & $5,00 \mathrm{abA}$ & $3,00 \mathrm{aA}$ & $3,16 \mathrm{aA}$ & $2,00 \mathrm{aA}$ & $30,73 \mathrm{aA}$ & $28,23 \mathrm{aA}$ & $29,33 \mathrm{aA}$ \\
\hline \multirow[t]{2}{*}{ Basal } & $4,83 \mathrm{aA}$ & $5,86 \mathrm{aA}$ & $6,00 \mathrm{aA}$ & $1,66 \mathrm{bA}$ & $3,33 \mathrm{aA}$ & $3,00 \mathrm{abA}$ & $28,83 \mathrm{aA}$ & $20,83 \mathrm{aA}$ & $22,33 \mathrm{aA}$ \\
\hline & -------------- & $\operatorname{MSPA}(\mathrm{g})$ & ---------------- & ---------- & IS (\%) & --------------- & & & \\
\hline Apical & $0,00 \mathrm{cB}$ & $1,45 \mathrm{aA}$ & $0,61 \mathrm{bB}$ & $0,00 \mathrm{bC}$ & $35,00 \mathrm{aA}$ & 23,66abA & & & \\
\hline Mediana & $2,10 \mathrm{aA}$ & $1,87 \mathrm{aA}$ & $1,55 \mathrm{aA}$ & $60,00 \mathrm{aA}$ & $26,66 \mathrm{bA}$ & $28,33 \mathrm{bA}$ & & & \\
\hline Basal & $1,54 \mathrm{aA}$ & $1,92 \mathrm{aA}$ & $1,61 \mathrm{aA}$ & $30,00 \mathrm{aB}$ & $33,33 \mathrm{aA}$ & $22,33 \mathrm{aA}$ & & & \\
\hline
\end{tabular}

Médias seguidas de mesmas letras, minúsculas nas linhas e maiúsculas nas colunas, para cada característica avaliada, não diferem entre si, pelo teste de Tukey (5\%).

enraizamento (PER), sugerindo que este material apresentava algum impedimento tanto para a indução quanto para a emissão das raízes adventícias. Porém, para a aceroleira, não há referências na literatura que descrevam a existência de impedimentos físicos ou qualquer alusão ao enraizamento de ramos lenhosos que limitem o enraizamento.

As estacas colhidas da posição mediana e basal do ramo apresentaram maior proporção de gemas que não brotaram (GNB), o que refletiu em um menor desenvolvimento da parte aérea destas mudas (Tabela 2).

Nas estacas colhidas da parte mediana dos ramos, verificouse uma tendência de superioridade quanto às variáveis estudadas para as estacas de $15 \mathrm{~cm}$ e de $20 \mathrm{~cm}$ em relação às de $10 \mathrm{~cm}$ (Tabela 2). Estes dados sugerem que a maior quantidade de reservas nutritivas teria sido o fator responsável pela maior predisposição para o enraizamento adventício, bem como para a emissão da brotação na parte aérea (Fachinelo et al., 1995 e Hartmam et al., 1997).

Nas estacas, colhidas em todas as posições, houve brotamento generalizado logo após o plantio, observando-se, em seguida, a morte de todas as estacas com $10 \mathrm{~cm}$ de comprimento, colhidas na posição apical. Isso deve ter ocorrido provavelmente porque o enraizamento das estacas deve ocorrer antes da emissão dos brotos (Hartman et al., 1997). A formação de novas estruturas na parte aérea da estaca funciona como um forte dreno consumidor das reservas de carboidratos e compostos nitrogenados; portanto, o seu surgimento antes da emissão das raízes na base da estaca pode levar à exaustão destas reservas, resultando na morte das estacas.

O número de ramos desenvolvidos nas estacas basais foi ligeiramente maior nas de $15 \mathrm{~cm}$, do que nas estacas de 10 e $20 \mathrm{~cm}$ (Tabela 2).

Com relação ao número de brotos, Gondim et al. (2001) afirmam que o menor número de ramos desenvolvidos na estaca, principalmente os laterais, seria uma das vantagens do sistema, pois reduziria o número de podas de condução na fase de formação da copa da planta.

O número de folhas foi estatisticamente semelhante em todas as estacas que sobreviveram, independentemente da posição no ramo e do comprimento (Tabela 2).

O índice de sobrevivência de estacas (Tabela 2), avaliado ao final do experimento, foi maior naquelas com $10 \mathrm{~cm}$ de comprimento e retiradas na posição mediana do ramo. Este fato ocorreu possivelmente em função de a parte mediana do ramo ter acumulado quantidade suficiente de reservas nutritivas para suportar o desenvolvimento das raízes e dos brotos. Ao mesmo tempo, a menor quantidade de tecido vivo (apenas $10 \mathrm{~cm}$ de ramo) demanda menor quantidade de nutrientes para sobreviver e menor área sujeita à perda de umidade. Ao se compararem estacas com $10 \mathrm{~cm}$ de comprimento, verificou-se grande contraste no índice de sobrevivência, que passou de $0 \%$ nas apicais, para $60 \%$ nas retiradas da parte mediana dos ramos (destacando-se como o maior índice entre os tratamentos) e para 30\% nas da parte basal.

Quanto à massa seca da parte aérea, que é um indicativo do vigor da muda, verificou-se maior acúmulo em estacas colhidas da posição mediana e basal de 10 e $15 \mathrm{~cm}$ de comprimento, em comparação com as colhidas na parte apical dos ramos (Tabela 2).

Os dados da massa da matéria seca das raízes (Tabela 2), que auxiliam na avaliação do vigor da muda, indicam que as estacas colhidas na parte apical apresentam maior valor à medida que se aumenta 0 tamanho da estaca. Por sua vez, as estacas com $10 \mathrm{~cm}$ de comprimento e colhidas na parte mediana do ramo foram as que apresentaram a maior massa seca de raízes.

A variação no vigor e o grande contraste no índice de sobrevivência entre as estacas com $10 \mathrm{~cm}$ de comprimento indicam que são viáveis, mas, ao mesmo tempo, muito sensíveis no que se refere à posição do ramo em que são colhidas.

\section{CONCLUSÃO}

Estacas com $10 \mathrm{~cm}$ de comprimento retiradas da porção mediana dos ramos são apropriadas para a produção de mudas de aceroleira por estaquia, nas condições de casa de vegetação com nebulização intermitente.

\section{REFERÊNCIAS}

BEZERRA, J.E.F.; LEDDERMAN, I.E.; ASCHOFF, M.N.A.; SANTOS, V.F. Efeito do tamanho da estaca herbácea e do ácido indolbutírico no enraizamento da acerola (Malpighia glaba L.) em duas épocas de estaquia. Revista Brasileira de Fruticultura, Cruz das Almas, v.13, n.3.p.157-163, 1991.

BRAGA, M.F.; CALDAS, L.S.; HABE, M.H. Estabelecimento de acerola (Malpighia glaba L.) in vitro: Efeito do clone e do explante. Revista Brasileira de Fruticultura, Cruz das Almas, v.19, n.3. p.335-346, 1997.

COSTA, C.M.C.; MAIA, L.C.; CAVALCANTE, U.M.T.; NOGUEIRA, R.J.M.C. Influência de fungos micorrízicos arbusculares sobre o crescimento de dois genótipos de aceroleira (Malpighia emarginata D.C). Pesquisa Agropecuária Brasileira, Brasília, v.36, n.6, p.893-901, 2002.

FACHINELLO, J.C.; HOFFMANN,A.; NACHTIGAL, J.C.; KERSTEN, E.; FORTES, G.R. Propagação de plantas frutíferas de clima temperado. 2. ed. Pelotas: Editora e Gráfica UFPEL, 1995.p.41-125.

GOMES, J.E.; PERECIN, D.; MARTINS, A.B.G; IGNÁCIO N. Enraizamento de estacas herbáceas de genótipos de acerola em câmara de nebulização intermitente tratadas com ácido indolbutírico em duas épocas. Revista Brasileira de Fruticultura, Jaboticabal, 
v.22, n.3, p.407-412, 2000

GONDIM, T.M. de S.; LEDO, F.J. da S.; CAVALCANTE, M. de J.B.; SOUZA, A. das G. C. Efeito da porção do ramo e comprimento de estacas na propagação vegetativa de plantas de cupuaçu. Revista Brasileira de Fruticultura, Jaboticabal, v.23, n.1, p.203-205, 2001.

GONZALEZ, M.G.N.; PÍPOLO, V.C.; MALAGUIDO, A.B. Influencia da consistência física no enraizamento de estacas de aceroleira (Malpighia emarginata). In: CONGRESSO BRASILEIRO DE FRUTICULTURA, 12., 1994, Salvador, BA. Anais... Salvador: SBF, 1994. p.77.

HARTMAN, H.T.; KESTER, D.E.; FRED JR, T.D.; GENEVE, R.L. Plant propagation: principles and practices. New jersey: Prentice Hall, 1997.770p.
LIMA, A.C.S.; ALMEIDA, F.A.C.; ALMEIDA, F.C.G. Estudo sobre o enraizamento de estacas de acerola (Malpighia glaba L.). Revista Brasileira de Fruticultura, Cruz das Almas, v.14, n.1. p.7-13, 1992.

NICOLOSO, F.T.; FORTUNATO, R.P.; FOGAÇA, M.A.F. Influencia da posição da estaca no ramo sobre o enraizamento de Pfaffia glomerata (Spreng.) Pedersen em dois substratos. Ciência Rural, Santa Maria, v.29, n.2, p. 277-283, 1999.

PAIVA, J.R.; PAIVA, W.O.; CORDEIRO, E.R.; SABRY NETO, H. Parâmetros genéticos em progênies de polinização livre de acerola. Pesquisa Agropecuária Brasileira, Brasília, v.34, n.4, abril. 1999. p.629-634. 